\title{
Lung function is associated with minimal EQ-5D changes over time in patients with systemic sclerosis
}

\author{
Jacopo Ciaffi ${ }^{1,2,3}$ (D) Nina M. van Leeuwen ${ }^{1}$ - Sophie I.E. Liem ${ }^{1} \cdot$ Maarten K. Ninaber $^{4} \cdot$ Tom W.J. Huizinga $^{1}$ • \\ Jeska K. de Vries-Bouwstra ${ }^{1}$
}

Received: 24 October 2019 / Revised: 11 January 2020 / Accepted: 16 January 2020 / Published online: 24 January 2020

(C) The Author(s) 2020

\begin{abstract}
In systemic sclerosis $(\mathrm{SSc})$ therapeutic efforts are often directed to prevent progressive respiratory impairment, but it is unclear to what extent changes in pulmonary function tests (PFTs) are associated with health-related quality of life (HRQoL). The aim of our study is to evaluate how modifications in PFTs contribute to longitudinal variations in HRQoL, assessed through the multidimensional questionnaire EQ-5D, in patients with SSc. We included SSc patients with forced vital capacity (FVC\%), diffusing capacity of the lungs for carbon monoxide (DLCO\%) and EQ-5D assessed in at least two visits. The EQ-5D consists of two parts, a utility score ranging from -0.59 to 1 , and a $0-100$ Visual Analogue Scale (VAS). Higher values represent better health. The association between changes in $\mathrm{FVC} \%$ and $\mathrm{DLCO} \%$, and evolution of EQ-5D over time, was investigated using generalized estimating equations. Three hundred seventy-eight patients were included, accounting for a total of 1619 measurements. The models showed that improvement in FVC\% is significantly associated with increase in both utility score $(\beta=0.001$; $95 \%$ CI 0.000 to $0.002 ; p=0.003)$ and VAS over time $(\beta=0.188 ; 95 \%$ CI 0.111 to $0.264 ; p<0.001)$. Moreover, improvement in DLCO $\%$ is longitudinally associated with increase in utility score $(\beta=0.001 ; 95 \% \mathrm{CI} 0.000$ to $0.002 ; p=0.038)$, while the results for VAS were non-significant ( $\beta=0.020 ; 95 \%$ CI -0.079 to $0.120 ; p=0.690)$. We show that change in PFTs has a significant, although minor, impact on HRQoL as measured by EQ-5D in SSc.
\end{abstract}

\section{Key Points}

- In patients with SSc, changes in PFTs have a significant, although minor, impact on HRQoL.

- In patients with SSc-ILD, the perception of HRQoL is nearly not influenced by changes in pulmonary function.

- The use of generic questionnaires might not be sensitive enough to evaluate the impact on quality of life of therapies targeting specific SSc manifestations.

Keywords Health-related quality of life $\cdot$ Interstitial lung disease $\cdot$ Respiratory function tests $\cdot$ Systemic sclerosis

Jacopo Ciaffi

j.ciaffi@lumc.nl; jacopo.ciaffi91@gmail.com

1 Department of Rheumatology, Leiden University Medical Center, Leiden, the Netherlands

2 Rheumatology Unit, Azienda Policlinico of Modena, University of Modena and Reggio Emilia, Modena, Italy

3 Medicine and Rheumatology Unit, IRCCS Istituto Ortopedico Rizzoli, Bologna, Italy

4 Department of Pulmonology, Leiden University Medical Center, Leiden, the Netherlands

\section{Introduction}

Interstitial lung disease (ILD) is frequent in systemic sclerosis ( $\mathrm{SSc}$ ), with a prevalence reported between 35 and 52\% [1]. Considering that ILD represents a major cause of mortality in SSc [2], preventing the progression of respiratory impairment is of utmost importance to improve life expectancy of SSc patients and it has been the target of several investigational studies. Pulmonary function tests (PFTs) were always, although variably, included among the assessed outcomes, and, in clinical practice, PFTs have an established role in screening and follow-up of SSc patients [3]. 
Lung involvement is also a major contributor to morbidity in SSc [4], thus it is conceivable that pulmonary complications may affect health-related quality of life (HRQoL). Among the generic instruments available to assess HRQoL in patients with SSc, short-form 36 (SF-36), health assessment questionnaire (HAQ), and EQ-5D are widely used for their reliability and validity. Feasibility, acceptability, and construct validity of EQ-5D have been demonstrated in SSc patients and, when compared with the scleroderma HAQ and with SF-36, the EQ5D was shown to cover all domains [5]. Tools to assess HRQoL are also adopted in randomized trials, typically as secondary outcomes, remarking the importance of evaluating the efficacy of novel therapies also in terms of HRQoL improvement. An association between impaired pulmonary function and decreased EQ-5D has been described in SSc [6], in patients with other respiratory diseases [7], and also in lung-healthy individuals [8]. Nevertheless, the extent of contribution given by changes in PFTs over time to the evolution of HRQoL in SSc patients is largely unknown.

Therefore, the aim of our study is to retrospectively evaluate how changes in PFTs contribute to longitudinal variations in HRQoL assessed using the multidimensional questionnaire EQ-5D in a large cohort of patients with SSc, at first considering the whole population and then only patients with ILD. Secondly, based on previously described minimum clinically important difference (MCID) [9], we determined the number of patients in the entire cohort experiencing relevant fluctuations in EQ-5D utility score, and whether these could be explained by changes in PFTs or not.

\section{Materials and methods}

We conducted a retrospective observational study including adult patients enrolled in the Leiden Combined Care in SSc (CCISS) cohort [10] and having a first visit performed between 2 April 2009 and 30 April 2018. Since 2009, at Leiden University Medical Center (LUMC), SSc patients are followed in a standardized care pathway, consisting of yearly multidisciplinary medical consultations and extensive workup, comprising PFTs, $\mathrm{x}$-ray and high-resolution computed tomography (HRCT) of the thorax, electrocardiogram, echocardiography, and 6-min walk test. As part of this comprehensive evaluation, dedicated questionnaires are proposed on an annual basis to all patients, with the aim of assessing HRQoL. For the purpose of this study, follow-up data collected until 2 May 2019 were analysed. Being interested in longitudinal variations, we selected patients with at least one baseline and one follow-up visit in which PFT measurements were performed and complete EQ-5D utility scores and VAS were obtained. All patients had to fulfil the 2013 ACR/EULAR classification criteria for SSc [11]. For cases enrolled before their availability, the abovementioned criteria were retrospectively applied.

Of the 697 patients enrolled in the CCISS cohort until 30 April 2018, 321 were excluded because of not meeting the 2013 ACR/EULAR classification criteria or lack of at least one follow-up visit with complete PFTs and EQ-5D obtained before 2nd May 2019 (Fig. 1).

Research on the CCISS cohort is approved by the Ethics Committee of LUMC (approval number P09.003), and all patients gave written informed consent. The study was conducted in accordance with the principles of the Declaration of Helsinki.

All data were collected in an electronic database dedicated to the CCISS cohort. In case of missing variables, medical records were checked. Demographic and clinical characteristics were gathered at the first visit included in the study and at each following time point. Disease duration was defined as time since the onset of first sign or symptom attributable to SSc different from Raynaud's phenomenon. Patients were categorized as never, former, or current smokers, and the presence of pulmonary comorbidities, namely chronic obstructive pulmonary disease, asthma, and a current or recent history of lung cancer, was also described. Disease subset, presence of ILD or pulmonary arterial hypertension (PAH) and skin fibrosis involving the anterior chest or abdomen were reported. Forced vital capacity (FVC\%) and single-breath diffusing capacity of the lungs for carbon monoxide corrected for haemoglobin (DLCO\%) were expressed as percentages of the predicted reference values in accordance with published standards $[12,13]$. The diagnosis of ILD was based on evidence of compatible interstitial abnormalities detected at HRCT of the thorax and reported by an experienced thoracic radiologist.

In the CCISS cohort, the EQ-5D-3L version is used. The questionnaire consists of two distinct parts. The first part is composed by five domains: mobility, self-care, usual activities, pain/discomfort, anxiety/depression. Patients can choose, for each dimension, among three severity levels: no problems, some problems, extreme problems. A sum utility score is calculated using nation-specific algorithms [14]. The Dutch tariff [15] was applied in the present study. Results vary from -0.59 to 1 . Negative scores indicate patient's perception of a health status worse than death, while a score of 1 means perfect health. The second part of the questionnaire consists of a single visual analogue scale (VAS) through which patients are asked to rate their health of the day from 0 to 100 . Higher values represent better health. For the EQ-5D utility score, MCID in SSc has been determined [9], corresponding to an increase of 0.05 to 0.10 for minimally improved categories, and to a decrease of 0.12 to 0.14 for minimally deteriorated categories.

Patients' characteristics were reported using descriptive statistics with mean and standard deviation, or median and 
Fig. 1 Patients included in the study. CCISS: Combined Care in Systemic Sclerosis; PFTs: pulmonary function tests; HRCT: high-resolution computed tomography; ILD: interstitial lung disease; FVC: forced vital capacity

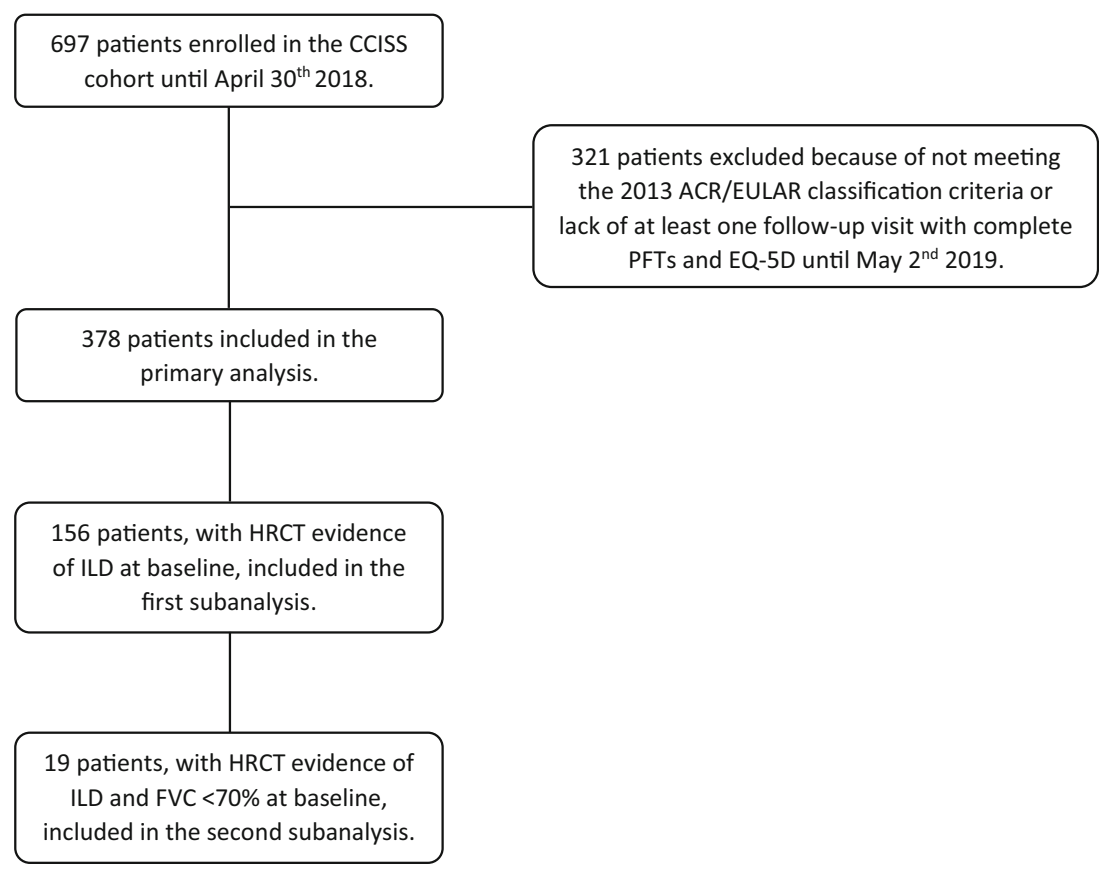

interquartile range (IQR), expressed when appropriate. The association over time between PFTs and EQ-5D was analysed using generalized estimating equations (GEEs). A model with linear response and autoregressive correlation structure was chosen. Two longitudinal models were set to analyse the entire population, with either EQ-5D utility score or VAS as dependent variable. Both models included $\mathrm{FVC} \%$ and $\mathrm{DLCO} \%$ as predictors, and were adjusted for age, disease duration, smoking status, presence of pulmonary comorbidities, and skin fibrosis involving anterior chest or abdomen. In subanalyses, the same models were applied to all patients with ILD and to the subgroup of patients with ILD and FVC $<70 \%$. A $p<0.05$ was considered significant.

\section{Results}

We included 378 patients (301 women, 77 men) with a minimum of 2 and a maximum of 11 annual visits, accounting for a median follow-up of 3.7 years (IQR 1.9-6.4) and a total of 1619 measurements (Table 1). Mean age at first visit included in the study was $53.1 \pm 15.4$ years, and median disease duration was 3.8 years (IQR 1.1-10.5). The majority of patients had the limited cutaneous disease subset (57\%), and ILD was present in 156 cases $(41 \%)$, whereas PAH was considerably less common (3\%). At baseline, mean FVC \% was $99.1 \pm 20.0 \%$ and mean DLCO $\%$ was $66.1 \pm$ $16.7 \%$. Regarding HRQoL, median EQ-5D utility score was 0.77 (IQR $0.65-0.84$ ) and median EQ-5D VAS was 70 (IQR 55-84).

The GEE models (Table 2) showed a significant association between increase of FVC\% and improvement of EQ-5D over time, in both its utility score and VAS components. The $\beta$ coefficients demonstrated how a patient with a $1 \%$ higher FVC\% was expected to have a 0.001 (95\% CI 0.000 to $0.002 ; p=0.003$ ) higher EQ-5D utility score and a 0.188 (95\% CI 0.111 to $0.264 ; p<0.001$ ) higher VAS. Furthermore, a significant association between increased DLCO \% and improvement of EQ-5D utility score was found, while the results with VAS as dependent variable were nonsignificant. For each 1\% increase in DLCO \%, a 0.001 (95\% CI 0.000 to $0.002 ; p=0.038$ ) growth in utility score and a 0.020 increase in VAS ( $95 \%$ CI -0.079 to $0.120 ; p=0.690$ ) were expected.

In the first subanalysis, 156 patients with ILD and 715 measurements were included. The GEE models (Table 3) showed a significant association between increase of $\mathrm{FVC} \%$ and improvement of VAS over time $(\beta$ coefficient $=0.167$; $95 \%$ CI 0.058 to $0.277 ; p=0.003$ ). In the second subanalysis, 19 patients with ILD and FVC $<70 \%$ were included, accounting for 94 measurements. The GEE models (Table 3) did not show any significant association between changes in $\mathrm{FVC} \%$ or DLCO\% and evolution of EQ-5D.

In the studied population, $72 \%$ of patients experienced one or more EQ-5D utility score changes consistent with MCID for improvement $(\geq 0.05)$ or worsening $(\leq 0.12)$, between any two consecutively available time points. In particular, utility score increase was observed in $111(30 \%)$ and decline in 39 (10\%), while 122 patients (32\%) experienced both variations during follow-up. EQ-5D changes compatible with MCID were identified in a total of 519 measurements. Of these, 317 (61\%) were improvements and 202 (39\%) were worsening. According to the $\beta$ coefficients shown by the GEE models in the entire population, in one case only, the FVC\% increase 
Table 1 Baseline characteristics of the studied population

\begin{tabular}{|c|c|c|c|}
\hline Patients characteristics & $\begin{array}{l}\text { All patients } \\
n=378\end{array}$ & $\begin{array}{l}\text { ILD } \\
n=156\end{array}$ & $\begin{array}{l}\text { ILD and } \mathrm{FVC}<70 \% \\
n=19\end{array}$ \\
\hline \multicolumn{4}{|l|}{ Demographic } \\
\hline Women, $n(\%)$ & $301(80)$ & $122(78)$ & $13(68)$ \\
\hline Age (years), mean (SD) & $53.1(15.4)$ & $54.7(15.3)$ & $50(13.8)$ \\
\hline Disease duration (years), median (IQR) & $3.8(1.1-10.5)$ & $4.5(1.3-11.3)$ & $7.5(3.6-14.2)$ \\
\hline BMI, mean (SD) & $25.0(4.4)$ & $25.0(4.3)$ & $27.4(6.0)$ \\
\hline Never smokers, $n(\%)$ & $175(46)$ & $71(46)$ & $12(63)$ \\
\hline Former smokers, $n(\%)$ & $133(35)$ & $64(41)$ & $7(37)$ \\
\hline Current smokers, $n(\%)$ & $70(19)$ & $21(13)$ & 0 \\
\hline \multicolumn{4}{|l|}{ Clinical } \\
\hline lcSSc, $n(\%)$ & $214(57)$ & $73(47)$ & $6(32)$ \\
\hline $\mathrm{dcSSc}, n(\%)$ & $99(26)$ & $63(40)$ & $9(47)$ \\
\hline ssSSc, $n(\%)$ & $65(17)$ & $20(13)$ & $4(21)$ \\
\hline mRSS, median (IQR) & $4(0-6)$ & $4(1-6)$ & $4(0-7)$ \\
\hline ILD, $n(\%)$ & $156(41)$ & $156(100)$ & $19(100)$ \\
\hline PAH, $n(\%)$ & $11(3)$ & $5(3)$ & $2(10)$ \\
\hline Skin fibrosis of anterior chest or abdomen, $n(\%)$ & $26(7)$ & $15(10)$ & $3(16)$ \\
\hline Pulmonary comorbidities, $n(\%)$ & $30(8)$ & $7(4)$ & $1(5)$ \\
\hline $\mathrm{Hb}(\mathrm{mmol} / \mathrm{L})$, mean $(\mathrm{SD})$ & $8.1(0.8)$ & $8.1(0.9)$ & $8.2(0.9)$ \\
\hline \multicolumn{4}{|l|}{ Pulmonary function tests } \\
\hline $\mathrm{FVC} \%$, mean $(\mathrm{SD})$ & $99.1(20.0)$ & $93.0(21.1)$ & $59.9(9.3)$ \\
\hline DLCO $\%$, mean $(\mathrm{SD})$ & $66.1(16.7)$ & $59.6(16.6)$ & $41.1(13.3)$ \\
\hline \multicolumn{4}{|l|}{ Quality of life } \\
\hline EQ-5D utility score, median (IQR) & $0.77(0.65-0.84)$ & $0.73(0.65-0.83)$ & $0.65(0.33-0.81)$ \\
\hline EQ-5D VAS, median (IQR) & $70(55-80)$ & $70(51-80)$ & $51(35-70)$ \\
\hline
\end{tabular}

Disease duration is considered as time since onset of first non-Raynaud's sign or symptom

$S D$ standard deviation, IQR interquartile range, $B M I$ body mass index, $l c S S c$ limited cutaneous systemic sclerosis, $d c S S c$ diffuse cutaneous systemic sclerosis, $s S S S c$ sine scleroderma systemic sclerosis, $m R S S$ modified Rodnan skin score, ILD interstitial lung disease, $P A H$ pulmonary artery hypertension, $F V C \%$ forced vital capacity percentage predicted, $D L C O \%$ diffusing capacity of the lungs for carbon monoxide percentage predicted, $V A S$ visual analogue scale

alone could account for the $\geq 0.05$ change in EQ-5D compatible with relevant improvement.

Table 2 Association of lung function with EQ-5D over time in the entire population

\begin{tabular}{lrr}
\hline & $\beta$ coefficient $(95 \% \mathrm{CI})$ & $p$ value \\
\hline Outcome: utility score over time & \\
FVC\% & $0.001(0.000$ to 0.002$)$ & 0.003 \\
DLCO\% & $0.001(0.000$ to 0.002$)$ & 0.038 \\
Outcome: VAS over time & $<0.001$ \\
FVC\% & $0.188(0.111$ to 0.264$)$ & 0.690 \\
DLCO\% & $0.020(-0.079$ to 0.120$)$ & \\
\hline
\end{tabular}

Generalized estimating equations results, adjusted for age, disease duration, smoking status, presence of pulmonary comorbidities and skin fibrosis involving anterior chest or abdomen

$F V C \%$ forced vital capacity percentage predicted, $D L C O \%$ diffusing capacity of the lungs for carbon monoxide percentage predicted, $C I$ confidence interval, VAS visual analogue scale

\section{Discussion}

We analysed the extent of contribution given by PFTs to change in HRQoL over time in all SSc patients enrolled in the CCISS cohort, then in SSc patients with ILD, and in the subgroup of patients with ILD and FVC $<70 \%$. Our findings demonstrate a statistically significant, but minor, impact of improvement in $\mathrm{FVC} \%$ and DLCO\% on HRQoL in SSc. Specifically, in the studied population, improvement of FVC\% is associated with increase in both EQ-5D utility score and VAS over time, and improvement of DLCO\% is associated with increase in EQ-5D utility score. Interestingly, in patients with SSc-ILD, the only significant finding was the association between changes of $\mathrm{FVC} \%$ and variations in VAS, while no significant result was observed in the subgroup of patients with ILD and $\mathrm{FVC}<70 \%$. A possible explanation is that, in the subanalyses, we were underpowered to detect other small but significant associations similar to those found in the entire population. 
Analysing all patients, we found that for a $1 \%$ increase in either $\mathrm{FVC} \%$ or $\mathrm{DLCO} \%$, a 0.001 improvement in utility score is expected. According to the previously described MCID for EQ-5D utility score [9], our results indicate that a substantial variation in FVC\% or in DLCO\% would be needed to determine a change in EQ-5D utility score approaching MCID. In particular, the magnitude of change required to reach MCID for worsening is unreasonable, being equal to a $120 \%$ deterioration in FVC\% or DLCO\%, whereas the $50 \%$ increase necessary to explain MCID for improvement is extremely rare in clinical practice. Taken as a whole, these results indicate that other aspects contribute largely to SSc patients' perception of quality of life, even when ILD with ventilatory impairment is present. Consequently, we cannot expect drugs specifically targeting SSc-associated ILD to have an impact on general HRQoL large enough to approach EQ5D utility score MCID.

Analysing data from Scleroderma Lung Study I (SLS-I) and II (SLS-II), a MCID for FVC\% changes after 12 months in patients with SSc and ILD has been estimated. It corresponds to a change between 3 and $5.3 \%$ for improvement, and between -3 and $-3.3 \%$ for worsening [16]. When subjects who improved or worsened were compared, a statistically significant difference in patient reported outcomes was noted, suggesting a relationship between better pulmonary function and improvement of HRQoL. However, this analysis included a selected trial population, with evidence of ILD and

Table 3 Association of lung function with EQ-5D over time in 156 patients with ILD at baseline and in the subgroup of 19 patients with ILD and $\mathrm{FVC}<70 \%$ at baseline

$\beta$ coefficient $(95 \% \mathrm{CI}) \quad p$ value

Patients with ILD

Outcome: utility score over time

$$
\begin{array}{ll}
\text { FVC\% } & 0.001(0.000 \text { to } 0.003) \\
\text { DLCO } \% & 0.001(-0.001 \text { to } 0.003)
\end{array}
$$

Outcome: VAS over time

$$
\begin{array}{ll}
\text { FVC } \% & 0.167(0.058 \text { to } 0.277) \\
\text { DLCO } \% & -0.018(-0.174 \text { to } 0.138)
\end{array}
$$

0.823

Patients with ILD and FVC $<70 \%$

Outcome: utility score over time

$$
\begin{array}{lll}
\text { FVC } \% & 0.000(-0.005 \text { to } 0.004) & 0.971 \\
\text { DLCO } \% & 0.003(-0.004 \text { to } 0.010) & 0.351
\end{array}
$$

Outcome: VAS over time

$\begin{array}{lll}\text { FVC\% } & 0.370(-0.325 \text { to } 1.066) & 0.296 \\ \text { DLCO } \% & -0.364(-0.750 \text { to }-0.021) & 0.064\end{array}$

Generalized estimating equations results, adjusted for age, disease duration, smoking status, presence of pulmonary comorbidities and skin fibrosis involving anterior chest or abdomen

$F V C \%$ forced vital capacity percentage predicted, $D L C O \%$ diffusing capacity of the lungs for carbon monoxide percentage predicted, $C I$ confidence interval, VAS visual analogue scale symptoms of breathlessness, and the tools used to assess HRQoL were both generic and specific for respiratory manifestations, but EQ-5D was not comprised. Conversely, we studied an unselected cohort, with data collected over a considerably longer time span, and focusing the analysis on EQ$5 \mathrm{D}$ variation.

In line with our findings, a large international survey observed that patients with SSc frequently complain of impaired HRQoL but lung involvement is not among the most important factors influencing disease severity and daily life from the patient's perspective [17]. In the ASTIS trial [18], a significant difference in mean change of EQ-5D utility score was shown after 2 years for patients treated with haematopoietic stem cell transplantation compared with cyclophosphamide. When other patient-reported outcomes are considered, as in the recent SENSCIS trial [19], the superiority of antifibrotic therapy over placebo in lowering the annual rate of $\mathrm{FVC} \%$ decline was not reflected by a concurrent change in HRQoL measures.

Beyond SSc, EQ-5D has been used also in other rheumatic diseases. In rheumatoid arthritis it is valid, reliable, and responsive to change [20]. EQ-5D is associated with disease activity, functional impairment, coronary artery syndrome, depression, and anxiety [21]. Moreover, EQ-5D has been included among patient reported outcomes investigated in trials of new treatments [22] and to assess the efficacy of disease modifying antirheumatic drugs, indicating the need to achieve control of disease activity to improve patients' quality of life [23]. However, although EQ-5D has been widely applied to rheumatic diseases, the extent of contribution given by respiratory impairment to HRQoL in patients with lung involvement secondary to autoimmune rheumatic diseases is largely unknown.

Our research is not without limitations. The EQ-5D was not originally developed for SSc, neither for respiratory diseases. It is thus possible that EQ-5D is not sensitive enough to SScspecific factors. Moreover, we used the EQ-5D-3L version which, compared with the $5 \mathrm{~L}$ version, is less sensitive, less precise, and more prone to ceiling effect [24]. Finally, we took several factors into account, but we cannot exclude that in the complicated relationship between lung physiology and HRQoL, other confounders might play a role. Nevertheless, we also believe that our study has strengths. First, all PFTs were standardly and centrally obtained in the same department of our academic centre, ensuring quality of the measurements. Secondly, according to the inclusion criteria, we had no missing data in either dependent or independent variables and we could contribute information from a large number of patients with heterogeneous disease characteristics. As such we were able to include 1619 time points describing 378 patients.

In conclusion, studying a large and unselected cohort of SSc patients we demonstrated that changes in PFTs have a significant, although minor, impact on HRQoL in SSc. Our findings again underline the importance of treating lung involvement in SSc and also indicate that generic questionnaires 
might not be sensitive enough to evaluate the impact on HRQoL of therapies targeting specific SSc manifestations.

\section{Compliance with ethical standards}

\section{Disclosures None.}

Open Access This article is licensed under a Creative Commons Attribution 4.0 International License, which permits use, sharing, adaptation, distribution and reproduction in any medium or format, as long as you give appropriate credit to the original author(s) and the source, provide a link to the Creative Commons licence, and indicate if changes were made. The images or other third party material in this article are included in the article's Creative Commons licence, unless indicated otherwise in a credit line to the material. If material is not included in the article's Creative Commons licence and your intended use is not permitted by statutory regulation or exceeds the permitted use, you will need to obtain permission directly from the copyright holder. To view a copy of this licence, visit http://creativecommons.org/licenses/by/4.0/.

\section{References}

1. Bergamasco A, Hartmann N, Wallace L, Verpillat P (2019) Epidemiology of systemic sclerosis and systemic sclerosisassociated interstitial lung disease. Clin Epidemiol 11:257-273. https://doi.org/10.2147/clep.s191418

2. Tyndall AJ, Bannert B, Vonk M, Airo P, Cozzi F, Carreira PE, Bancel DF, Allanore Y, Muller-Ladner U, Distler O, Iannone F, Pellerito R, Pileckyte M, Miniati I, Ananieva L, Gurman AB, Damjanov N, Mueller A, Valentini G, Riemekasten G, Tikly M, Hummers L, Henriques MJ, Caramaschi P, Scheja A, Rozman B, Ton E, Kumanovics G, Coleiro B, Feierl E, Szucs G, Von Muhlen CA, Riccieri V, Novak S, Chizzolini C, Kotulska A, Denton C, Coelho PC, Kotter I, Simsek I, de la Pena Lefebvre PG, Hachulla E, Seibold JR, Rednic S, Stork J, Morovic-Vergles J, Walker UA (2010) Causes and risk factors for death in systemic sclerosis: a study from the EULAR Scleroderma Trials and Research (EUSTAR) database. Ann Rheum Dis 69(10):1809-1815. https:// doi.org/10.1136/ard.2009.114264

3. Chowaniec M, Skoczynska M, Sokolik R, Wiland P (2018) Interstitial lung disease in systemic sclerosis: challenges in early diagnosis and management. Reumatologia 56(4):249-254. https:// doi.org/10.5114/reum.2018.77977

4. Khanna D, Seibold J, Goldin J, Tashkin DP, Furst DE, Wells A (2017) Interstitial lung disease points to consider for clinical trials in systemic sclerosis. Rheumatology (Oxford, England) 56(suppl 5):v27-v32. https://doi.org/10.1093/rheumatology/kex203

5. Gualtierotti R, Ingegnoli F, Scalone L, Cortesi P, Bruschi E, Gerosa M, Meroni PL (2016) Feasibility, acceptability and construct validity of EQ-5D in systemic sclerosis. Swiss Med Wkly 146:w14394. https://doi.org/10.4414/smw.2016.14394

6. Mugii N, Someya F, Noto S, Hamaguchi Y, Matsushita T, Takehara K (2019) Availability of EuroQol-5-Dimensions-5-Level (EQ-5D$5 \mathrm{~L}$ ) as health-related QOL assessment for Japanese systemic sclerosis patients. Mod Rheumatol:1-6. https://doi.org/10.1080/ 14397595.2019.1640409

7. Szentes BL, Kreuter M, Bahmer T, Birring SS, Claussen M, Waelscher J, Leidl R, Schwarzkopf L (2018) Quality of life assessment in interstitial lung diseases: a comparison of the diseasespecific K-BILD with the generic EQ-5D-5L. Respir Res 19(1): 101. https://doi.org/10.1186/s12931-018-0808-x
8. Luzak A, Karrasch S, Wacker M, Thorand B, Nowak D, Peters A, Schulz H (2018) Association of generic health-related quality of life (EQ-5D dimensions) and inactivity with lung function in lunghealthy German adults: results from the KORA studies F4L and age. Qual Life Res 27(3):735-745. https://doi.org/10.1007/s11136017-1763-6

9. Kwakkenbos L, Fransen J, Vonk MC, Becker ES, Jeurissen M, van den Hoogen FH, van den Ende CH (2013) A comparison of the measurement properties and estimation of minimal important differences of the EQ-5D and SF-6D utility measures in patients with systemic sclerosis. Clin Exp Rheumatol 31(2 Suppl 76):50-56

10. Meijs J, Schouffoer AA, Ajmone Marsan N, Kroft LJ, Stijnen T, Ninaber MK, Huizinga TW, Vliet Vlieland TP, de Vries-Bouwstra JK (2016) Therapeutic and diagnostic outcomes of a standardised, comprehensive care pathway for patients with systemic sclerosis. RMD Open 2(1):e000159. https://doi.org/10.1136/rmdopen-2015000159

11. van den Hoogen F, Khanna D, Fransen J, Johnson SR, Baron M, Tyndall A, Matucci-Cerinic M, Naden RP, Medsger TA Jr, Carreira PE, Riemekasten G, Clements PJ, Denton CP, Distler O, Allanore Y, Furst DE, Gabrielli A, Mayes MD, van Laar JM, Seibold JR, Czirjak L, Steen VD, Inanc M, Kowal-Bielecka O, Muller-Ladner U, Valentini G, Veale DJ, Vonk MC, Walker UA, Chung L, Collier DH, Csuka ME, Fessler BJ, Guiducci S, Herrick A, Hsu VM, Jimenez S, Kahaleh B, Merkel PA, Sierakowski S, Silver RM, Simms RW, Varga J, Pope JE (2013) 2013 classification criteria for systemic sclerosis: an American College of Rheumatology/ European League against Rheumatism collaborative initiative. Arthritis Rheum 65(11):2737-2747. https://doi.org/10.1002/art. 38098

12. Laszlo G (1993) European standards for lung function testing: 1993 update. Thorax 48(9):873-876. https://doi.org/10.1136/thx.48.9. 873

13. Quanjer PH, Stanojevic S, Cole TJ, Baur X, Hall GL, Culver BH, Enright PL, Hankinson JL, Ip MS, Zheng J, Stocks J (2012) Multiethnic reference values for spirometry for the 3-95-yr age range: the global lung function 2012 equations. Eur Respir J 40(6): 1324 1343. https://doi.org/10.1183/09031936.00080312

14. Rabin R, Gudex C, Selai C, Herdman M (2014) From translation to version management: a history and review of methods for the cultural adaptation of the EuroQol five-dimensional questionnaire. Value Health 17(1):70-76. https://doi.org/10.1016/j.jval.2013.10. 006

15. Lamers LM, McDonnell J, Stalmeier PF, Krabbe PF, Busschbach JJ (2006) The Dutch tariff: results and arguments for an effective design for national EQ-5D valuation studies. Health Econ 15(10): 1121-1132. https://doi.org/10.1002/hec. 1124

16. Kafaja S, Clements PJ, Wilhalme H, Tseng CH, Furst DE, Kim GH, Goldin J, Volkmann ER, Roth MD, Tashkin DP, Khanna D (2018) Reliability and minimal clinically important differences of forced vital capacity: results from the Scleroderma Lung Studies (SLS-I and SLS-II). Am J Respir Crit Care Med 197(5):644-652. https:// doi.org/10.1164/rccm.201709-1845OC

17. Frantz C, Avouac J, Distler O, Amrouche F, Godard D, Kennedy AT, Connolly K, Varga J, Matucci-Cerinic M, Allanore Y (2016) Impaired quality of life in systemic sclerosis and patient perception of the disease: a large international survey. Semin Arthritis Rheum 46(1):115-123. https://doi.org/10.1016/j.semarthrit.2016.02.005

18. van Laar JM, Farge D, Sont JK, Naraghi K, Marjanovic Z, Larghero J, Schuerwegh AJ, Marijt EW, Vonk MC, Schattenberg AV, Matucci-Cerinic M, Voskuyl AE, van de Loosdrecht AA, Daikeler T, Kotter I, Schmalzing M, Martin T, Lioure B, Weiner SM, Kreuter A, Deligny C, Durand JM, Emery P, Machold KP, Sarrot-Reynauld F, Warnatz K, Adoue DF, Constans J, Tony HP, Del Papa N, Fassas A, Himsel A, Launay D, Lo Monaco A, Philippe P, Quere I, Rich E, Westhovens R, Griffiths B, Saccardi 
R, van den Hoogen FH, Fibbe WE, Socie G, Gratwohl A, Tyndall A (2014) Autologous hematopoietic stem cell transplantation vs intravenous pulse cyclophosphamide in diffuse cutaneous systemic sclerosis: a randomized clinical trial. Jama 311(24):2490-2498. https:// doi.org/10.1001/jama.2014.6368

19. Distler O, Highland KB, Gahlemann M, Azuma A, Fischer A, Mayes MD, Raghu G, Sauter W, Girard M, Alves M, ClerismeBeaty E, Stowasser S, Tetzlaff K, Kuwana M, Maher TM (2019) Nintedanib for systemic sclerosis-associated interstitial lung disease. N Engl J Med 380(26):2518-2528. https://doi.org/10.1056/ NEJMoa1903076

20. Hurst NP, Kind P, Ruta D, Hunter M, Stubbings A (1997) Measuring health-related quality of life in rheumatoid arthritis: validity, responsiveness and reliability of EuroQol (EQ-5D). Br J Rheumatol 36(5):551-559. https://doi.org/10.1093/rheumatology/ 36.5.551

21. Katchamart W, Narongroeknawin P, Chanapai W, Thaweeratthakul P (2019) Health-related quality of life in patients with rheumatoid arthritis. BMC Rheumatol 3:34. https://doi.org/10.1186/s41927019-0080-9

22. Keystone EC, Taylor PC, Tanaka Y, Gaich C, DeLozier AM, Dudek A, Zamora JV, Cobos JAC, Rooney T, Bono S, Arora V, Linetzky
B, Weinblatt ME (2017) Patient-reported outcomes from a phase 3 study of baricitinib versus placebo or adalimumab in rheumatoid arthritis: secondary analyses from the RA-BEAM study. Ann Rheum Dis 76(11):1853-1861. https://doi.org/10.1136/ annrheumdis-2017-211259

23. Jorgensen TS, Turesson C, Kapetanovic M, Englund M, Turkiewicz A, Christensen R, Bliddal H, Geborek P, Kristensen LE (2017) EQ-5D utility, response and drug survival in rheumatoid arthritis patients on biologic monotherapy: a prospective observational study of patients registered in the south Swedish SSATG registry. PLoS One 12(2):e0169946. https://doi.org/10.1371/ journal.pone.0169946

24. Janssen MF, Bonsel GJ, Luo N (2018) Is EQ-5D-5L better than EQ5D-3L? A head-to-head comparison of descriptive systems and value sets from seven countries. PharmacoEconomics 36(6):675697. https://doi.org/10.1007/s40273-018-0623-8

Publisher's note Springer Nature remains neutral with regard to jurisdictional claims in published maps and institutional affiliations. 